\title{
Tradução comentada de Malinche, de Rosario Castellanos: uma dupla correção na história
}

Marina Leivas Waquil

Resumo: Neste trabalho, com base na reflexão da tradução feminista (GODARD, 1989; SIMON, 2005; VON FLOTOW, 1997) e a partir da tradução comentada para o português do poema Malinche (CASTELLANOS, [1948-1971], 2004), propõe-se uma dupla correção na história da tradução: resgatar e destacar a voz de Rosario Castellanos, ainda não traduzida e publicada pelo mercado editorial brasileiro, e destacar uma das figuras históricas mais injustiçadas pelo discurso patriarcal, Malinche, personagem central do poema.

Palavras-chave: tradução feminista; Malinche; Rosario Castellanos.

\section{Introdução}

Em um texto já famoso nos Estudos da Tradução, Lori Chamberlain (1988) apresenta e discute exemplos que demonstram que diversas relações características da tradução foram, e são, baseadas e expressas por meio de estereótipos de gênero, que, metaforizados, são aplicados a conceitos que se tornaram, ao longo de séculos, fundamentais na reflexão sobre a tradução - como fidelidade, reprodução - e que mantêm relações de poder e violência em relação às mulheres e à tradução.

1 Pós-doutoranda no Programa de Pós-Graduação em Letras Estrangeiras e Tradução (LETRA), da Universidade de São Paulo (USP), desenvolve pesquisas na interface Linguística de Corpus, Tradução e Estudos de Gênero. É doutora e mestra na linha de pesquisa Lexicografia, Terminologia e Tradução: Relações Textuais pela Universidade Federal do Rio Grande do Sul (UFRGS) e fez doutorado sanduíche na Universidade Autônoma de Barcelona. Atua como tradutora e revisora e, nos últimos anos, vem se dedicando à pesquisa com foco em tradução feminista. 
Malinche $e^{2}$ talvez seja a perfeita epítome dessas metáforas: "mulher", "amante", "intérprete", "escrava", "traidora", foi transformada em símbolo de traição a seu próprio povo, o que teria feito por meio de seu trabalho como intérprete aos espanhóis e por ter se relacionado com o conquistador Hernán Cortés no período da conquista e da colônia espanhola no México. Trata-se, também, de exemplo de uma questão paradigmática para a tradução: é uma das poucas mulheres que é reconhecida por seu trabalho no campo da tradução, mas o que justifica esse reconhecimento é justamente uma visão negativa sobre sua figura e baseada nas consequências atribuídas a seu trabalho - a conquista espanhola do México (SIMON, 2005).

Malinche foi uma mulher que desenvolveu, por força das circunstâncias às quais foi submetida, grandes habilidades linguísticas: dominava o náuatle, língua dos astecas, e o maia, língua da península de Yucatán, que aprendeu quando foi vendida por comerciantes (que a haviam comprado de sua mãe) ao povo de Tabasco; posteriormente, ao ser entregue como um presente ao exército do conquistador Hernán Cortés, Malinche aprenderia, também, a língua espanhola. Assim, por ter vivido em diversas sociedades e ter tido contato com diferentes povos indígenas ao longo de sua existência como escravizada, adquiriu facilidade com as línguas e suas culturas. Em sua história, é preciso destacar que, antes de sua junção com os espanhóis, já havia vivido e sofrido a supressão do povo maia pelos astecas, testemunhando diversos sacrifícios humanos realizados com fins e justificativas religiosas - a invasão/opressão espanhola, portanto, não foi a primeira que vivenciou.

Ao longo dos séculos, a Malinche se transformou, a partir de construções ficcionais sobre sua vida e seus feitos, em símbolo de uma corrupção que levou a um cruzamento de culturas, raças e produziu a desigual sociedade mexicana mestiça. É curioso que se fale muito e que se tenham criado diversas hipóteses em sua maioria negativas - sobre Malinche embora se saiba, de fato, muito pouco sobre ela. Os principais, mas poucos, registros que se tem da época e que mencionam Malinche correspondem, principalmente, aos escritos do cronista da época, Bernal Díaz del Castillo e sua "Historia Verdadera de la Conquista de la Nueva

2 Diversos nomes são utilizados em referência a essa figura história e há muitas teorias que os discutem/ explicam: Malinche, Malinalli, Malintzin, Malina, Doña Marina - este último, sim, utilizado pelos espanhóis a partir de seu batismo católico. Além disso, como destaca Kripper (2015), em espanhol, muitos são os "apelidos" atribuídos a ela: lengua, intérprete, traductora, traidora, amante, vendida, chingada, víctima, madre. Neste trabalho, optamos pelo uso de Malinche, em primeiro lugar, por ser o nome com que mais frequência encontramos referência a essa figura e, em segundo, para manter uma coesão com o título do poema de Rosario Castellanos aqui traduzido. 
España”, finalizada por volta de 1575, mas publicada apenas em 1632. Justamente na crônica de Bernal Díaz del Castilho entendemos que Malinche foi oferecida a Cortés junto a outras 20 mulheres e ouro pela tribo de Tabasco como presente em comemoração a um tratado de paz - essa, portanto, já não era a primeira troca/ venda à qual Malinche havia sido submetida em sua vida.

Esquecida por muito tempo, a partir do século XIX, quando surge entre a classe dominante mexicana o desejo e o intuito de buscar uma identidade nacional e a independência política, recupera-se o período da conquista, e, assim, o discurso que passou a contar a formação do México a partir da invasão dos espanhóis começou a incluir, com frequência, a figura de Malinche, de forma sexualizada, como amante do conquistador, traidora do povo indígena e mãe dos mestiços Malinche, nesse sentido, também simboliza a humilhação da conquista e é vista como a mulher que se associou sexual e politicamente com o conquistador, sendo responsável pela (re)produção de uma sociedade.

Apenas no século XX, quase 400 anos após o período em que viveu, começa-se a reviver, revisar e recontar sua história. A partir do trabalho de escritoras mulheres e feministas, entre as quais se destacam, por exemplo as chicanas - como Gloria Anzaldúa, Norma Alarcón, Carmen Taffola -, novos olhares e hipóteses foram produzidos com o objetivo de (tentar) fazer justiça a Malinche e mostrar as tensões, opressões e vitimizações às quais as mulheres foram, e são, submetidas em sociedades patriarcais, colonizadoras e opressoras. Assim, desde os anos 1970/1980, principalmente, a perspectiva feminista que passa ser incluída na reflexão sobre a tradução começa a dedicar especial atenção a Malinche enquanto figura sintética da injustiça perpetrada, ao mesmo tempo, em relação à mulher e à tradução. Com frequência, então, em escritos das principais téoricas da escola canadense de tradução feminista, como Luise Von Flotow e Sherry Simon, para citar algumas, encontramos uma reivindicação de uma nova leitura de Malinche e da tradução que 1) aponte ambas como vítimas de uma interpretação equivocada e misógina da história produzida em sociedades patriarcais e opressoras e que 2) exija, como reparo, uma visão contextualizada de sua vida e de suas reais possibilidades de agência, ao mesmo tempo, tirando a tradução do lugar de reprodução, de inferioridade e de submissão a um "original".

\section{Malinche, de Rosario Castellanos}

Rosario Castellanos nasceu na Cidade do México, em 1925, e, em seus 49 anos de vida, firmou-se como uma das mais importantes vozes da literatura 
mexicana. Trabalhou com diversos gêneros, incluindo romances (Balún Canán, 1957; Oficio de Tinieblas, 1962; Rito de Iniciación, publicado em 1996), poemas (como Trayectoria del polvo, 1946; Al pie de la letra, 1959, Livida lur, 1960), contos (Ciudad real, 1960; Los convidados de agosto, 1964; Álbum de familia, 1971), peças de teatro (Tablero de damas, pieza en un acto, 1952; El eterno femenino, 1975) e ensaios e artigos (Mujer que sabe latín..., 1973; El uso de la palabra, 1994). Em sua obra, dedicou-se a diversas questões e expressou-se com veêmencia sobre assuntos impactantes para a época, como as relações entre os povos indígenas e os brancos e o lugar atribuído à mulher na sociedade, na família, na educação e na literatura mexicanas. Como destaca Sara Guardia (2007, p. 11), entre seus principais temas, estavam a "marginalização cultural, política, social e econômica das mulheres e a pouca autoridade intelectual que lhes era concedida"; como resultado, sua voz foi fundamental na luta por espaço para a escrita de mulheres latino-americanas.

No livro Poesía no eres tú, uma compilação de obras poéticas escritas entre 1948 e 1971, mais especificamente no poema Malinche, Rosario Castellanos dá voz a 1) Malinche, que, no poema homônimo, fala em primeira pessoa, relatando uma parte inicial de sua vida, 2) e é intercalada pela voz de sua mãe, personagem central de seu destino, 3) e pela voz de um coro, marcada no poema por aspas, que, em lamento, relata e descreve a trágica cena de uma menina - provavelmente Malinche -, já morta, encontrando o pai, assassinado.

O foco de Castellanos no poema Malinche, portanto, diferentemente da maior parte das obras literárias que se dedicaram a essa figura, não é no famoso período em que foi escravizada e intérprete de Hernán Cortés, fase contada e deturpada durante séculos, mas, sim, em seu período pré-Cortés, pré-intérprete. No entanto, embora não descreva sua popular participação na conquista espanhola, o poema anuncia pontos da vida de Malinche que viriam a ser fundamentais para o curso de sua vida, como ser renegada pela mãe e vendida como escrava, o que acabaria levando-a às mãos dos espanhóis.

Temos, portanto, no poema de Castellanos, um resumo da primeira parte de sua vida: a morte do pai, que leva a mãe a juntar-se a outro homem, o padrasto, um homem que a rebaixa e a humilha e que a faria afastar-se da filha e culminaria com sua venda a comerciantes. Ao mesmo tempo, vemos, no poema, que a morte - real e simbólica - sempre rondou Malinche: perde o pai e morre, assim, para a mãe, que a renega, assim como para seu povo, do qual não passa mais a fazer parte uma vez que é "arrojada, expulsada". Morre, dessa forma, quando a mãe a vende a comerciantes, como um objeto, e passa a sentir-se uma escrava, uma ninguém, uma banida da vida. A morte simbólica que a mãe lhe causa é marca profunda destacada 
por Castellanos: Malinche se vê renegada justamente por sua semelhança com a mãe, o que, para esta, é inconcebível - a mãe se identifica na menina, odeia-a por isso e a arranca de si, de sua "entraña tibia". Como consequência, Malinche avança pela vida presa, "acorrentada", e o que muda nesse percurso parecem ser apenas seus donos, que vão desde comerciantes, que a compram da mãe, até Hernán Cortés, o que se sabe pela história, mas não pelo poema de Castellanos, que não adentra nesse período.

Nesse texto, uma releitura de Malinche, a possibilidade de interpretar o destino que teve como "língua" e intérprete de Cortés está no seu olhar para o futuro, em que se vê presa, entre correntes, enterrada com "rumores fúnebres" - isto é, pela infâmia, que a perseguirá mesmo depois de sua morte, através da história que a trata como traidora de seu povo, uma construção popular e misógina feita durante séculos sobre sua figura. O uso do termo "rumores", entretanto, coloca Malinche, a partir de sua voz em primeira pessoa, como questionadora dessa perspectiva que a vê como responsável pela queda de seu povo frente aos espanhóis - são boatos/ rumores que a injustiçam e que são atribuídos a uma mulher cujo destino nunca esteve livre de correntes, de prisão (real e simbólica), de escravidão.

O poema tem como último verso, uma vez mais, a marca de que o destino de Malinche estava dado desde o seu nascimento, visto como morte nas mãos da mãe, que, entre lágrimas, a decreta.

\section{A tradução de Malinche: uma escolha consciente}

A tradução desse poema, escrito por uma mulher mexicana - latino-americana - para o português brasileiro, é, por si só, uma estratégia de tradução feminista, no sentido de que dá voz a uma autora que, embora fundamental na literatura latino-americana, ainda não conta com publicação no mercado editorial brasileiro e, portanto, é pouco acessível ao grande público que lê em português. Por outro lado, não é raro encontrar artigos, dissertações e mesmo teses produzidas no Brasil com foco na obra de Rosario Castellanos, de modo que seu trabalho desperta interesse e atenção, mas ainda apenas no círculo acadêmico. Como destaca Olga Castro (2009), é um dos objetivos da tradução feminista denunciar e apontar a escrita de mulheres que é ignorada, ou mesmo silenciada, traduzindo-a e contribuindo para a mudança do cânone literário.

Além disso, se entendemos, como propõe Sherry Simon (2005), que a tradução é um tipo de ativismo literário, a "simples" escolha do texto e do(a) autor(a) fonte já é um elemento-chave na constituição da literatura que chega a 
um determinado público-leitor. Por isso, conscientemente, buscando destacar a produção de mulheres no contexto latino-americano, optou-se por traduzir uma voz ainda pouco ouvida no Brasil, a de Rosario Castellanos. Ao mesmo tempo, a escolha por um poema que tem como foco uma das figuras mais distorcidas da história latino-americana - e, não por coincidência, mulher - também é deliberada: busca-se, assim, contribuir para a revisão dessa distorção e para a recuperação de uma injustiça histórica e de fundo patriarcal.

O poema de Malinche, em versos livres, embora não tenha esquema e restrição métrica, apresenta ritmo e musicalidade, elementos evidentes na leitura feita pela própria autora ${ }^{3}$, que, com sua entonação, imprime a forte carga dramática intencionada e característica da vida de Malinche.

\section{Malinche}

Desde el sillón del mando mi madre dijo:

"Ha muerto".

Y se dejó caer, como abatida,

en los brazos del otro, usurpador, padrastro

que la sostuvo no con el respeto

que el siervo da a la majestad de reina

sino con ese abajamiento mutuo

en que se humillan ambos, los amantes,

los cómplices.

Desde la Plaza de los Intercambios

mi madre anunció: "Ha muerto".

\section{La balanza}

se sostuvo un instante sin moverse

y el grano de cacao quedó quieto en el arca

y el sol permanecía en la mitad del cielo

como aguardando un signo

que fue, cuando partió como una flecha,

el ay agudo de las plañideras.

\section{Malinche}

Sentada em seu trono, disse minha mãe:

"Morreu".

E se deixou cair, como abatida,

nos braços do outro, usurpador, padrasto, que a amparou não com o respeito que o servo dá à majestade da rainha mas com um rebaixamento mútuo com que se humilham ambos, os amantes, os cúmplices.

Da Praça dos Intercâmbios, anunciou minha mãe: "Morreu".

\footnotetext{
A balança

se manteve um instante sem mover-se e o grão de cacau ficou parado no cesto enquanto o sol permanecia na metade do céu como aguardando um sinal que veio, quando partiu, como uma flecha, o ai agudo das carpideiras.
}

3 Disponível em: https://www.palabravirtual.com/index.php?ir=ver voz1.php\&wid=1930\&t=Malin che\&p=Rosario + Castellanos\&o=Rosario + Castellanos Acesso em: 10 jun. 2020. 
"Se deshojó la flor de muchos pétalos, se evaporó el perfume,

se consumió la llama de la antorcha.

Una niña regresa, escarbando, al lugar en el que la partera depositó su ombligo.

Regresa al Sitio de los que Vivieron.

Reconoce a su padre asesinado, ay, ay, ay, con veneno, con puñal, con trampa ante sus pies, con lazo de horca.

Se toman de la mano y caminan, caminan perdiéndose en la niebla."

Tal era el llanto y las lamentaciones sobre algún cuerpo anónimo; un cadáver que no era el mío porque yo, vendida a mercaderes, iba como esclava, como nadie, al destierro.

\section{Arrojada, expulsada}

del reino, del palacio y de la entraña tibia de la que me dio a luz en tálamo legítimo y que me aborreció porque yo era su igual en figura y rango y se contempló en mí y odió su imagen y destrozó el espejo contra el suelo.

Yo avanzo hacia el destino entre cadenas y dejo atrás lo que todavía escucho: los fúnebres rumores con los que se me entierra.

Y la voz de mi madre con lágrimas, jcon lágrimas! que decreta mi muerte.
"Desfolhou-se a flor de muitas pétalas, evaporou-se o perfume, consumiu-se a chama da tocha.

Uma menina regressa, cavando, ao lugar em que a parteira enterrou seu umbigo.

Regressa ao Lugar dos que Viveram.

Reconhece seu pai assassinado, ai, ai, ai, com veneno, com punhal, com armadilha nos pés, com nó de forca.

Dão-se as mãos e caminham, caminham perdendo-se na névoa."

Assim eram o pranto e as lamentações sobre um corpo anônimo; um cadáver que não era o meu, porque fora vendida a comerciantes, escravizada, como uma ninguém, exilada.

Excluída, escorraçada

do reino, do palácio e das entranhas indiferentes daquela que me deu à luz em leito legítimo e que se enfadou comigo porque eu era igual a ela em forma e condição e se contemplou em mim e odiou sua imagem e destruiu o espelho contra o chão.

Eu avanço ao destino acorrentada e deixo para trás o que ainda escuto: os fúnebres rumores com os quais me enterram.

E a voz de minha mãe com lágrimas, - com lágrimas! que decreta minha morte.

\section{A questão da morte: quem morre?}

Um dos desafios da tradução se coloca já no primeiro verso, com uma possibilidade de ambiguidade na interpretação. Nesse verso - "Desde el sillón del mando mi madre dijo: 'Ha muerto'" -, sem indicação do sujeito morto por pronome pessoal, nome próprio ou mais informações contextuais, não podemos confirmar 
a quem se refere, mas, como em qualquer texto, principalmente o literário, temos a possibilidade de interpretá-lo, pois, ao longo do poema, vemos menção à morte do pai, assassinado, e à própria morte de Malinche, em relação à mãe, que a renega, e a seu povo, que se refere a ela com "rumores fúnebres".

Como resposta a essa questão interpretativa - embora se entenda a referência aqui à morte do pai de Malinche, uma vez que, a partir disso, a mãe se envolve com outro homem -, propõe-se a omissão de referência clara a esse sujeito, mantendo o verbo na terceira pessoa do singular e sem pronome pessoal: "Morreu". Sustenta-se, assim, a possibilidade de interpretação oferecida no poema-fonte de Castellanos e se mantém a relação ambígua quando a autora volta a referir-se a outro sujeito que morre, na quarta estrofe, em que lemos "mi madre anunció: 'Ha muerto"'. Nesse trecho, temos a possibilidade de interpretar que se trata de uma ênfase da mãe sobre a morte do pai, anunciando-a na Plaza de los Intercambios para justificar ao povo sua união com outro homem, mencionada na estrofe anterior. Por outro lado, como essa nova relação afastará Malinche de sua vida, é também uma possibilidade interpretar que é Malinche quem morre para a mãe. De modo a buscar manter essa dupla interpretação, decidiu-se manter a impessoalidade no verbo e, assim, o paralelismo que já se apresentava no poema de Castellanos - "Ha muerto"/"Ha muerto"; "Morreu"/"Morreu".

Em relação ao tema da morte, também se optou por reforçá-lo no trecho "en el que la partera depositó su ombligo", escolhendo como equivalente para "depositar" o verbo "enterrar", embora seja possível contar com o mesmo verbo "depositar" em português - assim, dá-se ênfase à morte, presente literal e simbolicamente ao longo do poema. Especificamente nessa parte, Malinche, ainda menina, cava e desenterra o cordão umbilical que a parteira havia enterrado ${ }^{4}$, regressando ao "Lugar dos que Viveram" - a morte? -, onde encontraria seu pai, assassinado.

\section{Marcas do feminino}

É fundamental no poema, e para a compreensão dessa personagem, a estrofe em que Malinche, em primeira pessoa, descreve o destino que lhe deram como objeto, vendida e escravizada:

4 Em sua leitura sobre a figura, Laura Esquivel, com o romance "Malinche" (2006), também relata que a parteira, na verdade a própria avó da menina Malinche, teria enterrado o cordão umbilical em uma tradição típica e simbólica indígena. 
Tal era el llanto y las lamentaciones sobre algún cuerpo anónimo; un cadáver que no era el mío porque yo, vendida a mercaderes, iba como esclava, como nadie, al destierro.

$\mathrm{Na}$ tradução, optou-se por focar na falta de agência que caracteriza o sujeito escravizado e que fundamenta o rumo da vida de Malinche. Assim, em vez de manter o verbo de movimento "ir" acompanhado do substantivo "esclava", escolheu-se incluir apenas o particípio passado, "escravizada", dando força à sujeição à qual a Malinche foi submetida - o que reforça a releitura feminista de tirá-la do campo da culpa e da responsabilidade: na escravidão não há agência, não há escolha, não há opção, então por que se questionam as "opções" e "escolhas" feitas por Malinche em relação a Cortés?

Para destacar essa questão, tira-se, também, na tradução, a ideia de movimento em "iba [...] al destierro", eliminando qualquer possibilidade de interpretá-la como uma alternativa, e, sim, destacando, mais uma vez, que se tratava de sofrer uma ação imposta por outros, isto é, estar, como consequência da escravidão, exilada.
Assim eram o pranto e as lamentações
sobre um corpo anônimo; um cadáver
que não era o meu, porque fora vendida
a comerciantes, escravizada,
como uma ninguém, exilada.

Finalmente, acrescentou-se ao substantivo "ninguém” a licença poética de um artigo feminino ("uma"), com o objetivo de afirmar sua condição de mulher e de contrapô-lo, propositalmente, ao substantivo "ninguém", que, assim como "nadie", em espanhol, não tem marcação de gênero gramatical e não é, segundo a norma padrão, acompanhado por artigo, definido ou infefinido. No entanto, levando em consideração que tanto na história de Malinche quanto no poema em questão o fato de ela ser mulher é fundamental, decidiu-se por reforçar essa questão, o que também se propõe como uma estratégia que contribui para a revisão do mito ao seu redor e que deve incluir o gênero como elemento impreterivelmente essencial na (falta de) escolha que teve Malinche em uma época com muito menos liberdade à mulher que se tem hoje - seria possível, enquanto mulher, indígena e escravizada, no início do século XVI, ter atuado de outra forma? 


\section{Mãe e filha}

Como mencionado, a relação entre mãe e filha tem fundamental importância no poema de Castellanos e é o fio condutor que explica a origem e o destino de Malinche. A negação de sua existência teria começado justamente na renegação da mãe, que a vende ainda menina a comerciantes, a partir do que começaria sua vida como escravizada. No poema, a escritora dedica uma estrofe para Malinche mostrar que sua sorte - destroçada junto ao espelho contra o chão - foi determinada desde o início pela renegação da mãe, que a odeia porque nela se identifica.

\author{
Arrojada, expulsada \\ del reino, del palacio y de la entraña tibia \\ de la que me dio a luz en tálamo legítimo \\ y que me aborreció porque yo era su igual \\ en figura y rango \\ y se contempló en mí y odió su imagen \\ y destrozó el espejo contra el suelo.
}

\author{
Excluída, escorraçada \\ do reino, do palácio e das entranhas indiferentes \\ daquela que me deu à luz em leito legítimo \\ e que se enfadou comigo porque eu era igual a ela \\ em forma e condição \\ e se contemplou em mim e odiou sua imagem \\ e destroçou o espelho contra o chão.
}

Em função disso, na tradução, optou-se por destacar essa interpretação da importância do desprezo da mãe como determinante na vida de Malinche; para tal, na expressão "entraña tibia", propôs-se um substantivo que marca e reforça a frieza e a renegação da mãe em relação à filha ("indiferente"): curiosamente, ao mesmo tempo que "tibio" pode significar cálido, morno, também tem o sentido de desapegado, frio. Opta-se, assim, por um substantivo que marca e reforça a frieza e a renegação da mãe em relação à filha.

Nessa mesma estrofe, o substantivo "rango", em adição à figura, impõe uma interpretação e uma decisão tradutórias: com possíveis equivalentes como "classe", "categoria", propõe-se "condição" para marcar a ideia de que, ambas, mãe e filha, vivem uma existência condicionada pelo fato de serem mulheres - nesse sentido, a categoria/condição mulher surge como empecilho para o amor da mãe - Laura Esquivel (2006), por exemplo, reconta a história de Malinche e dá à mãe um segundo filho, homem, a quem a mãe cuida e ama, como não conseguiu fazer com Malinche.

Com o objetivo de manter a sonoridade que consta no primeiro verso dessa estrofe, com "arrojada, expulsada", indica-se para "expulsada" não o equivalente literal em português "expulsa", mas "escorraçada", de modo a manter o paralelismo da última sílaba do particípio passado anterior, "arrojada" /"excluída". Assim, inverteu-se a força proposta no original para manter a sonoridade do verso: 
"escorraçada" como equivalente para "arrojada", e "excluída" como equivalente para "expulsada".

\section{Considerações finais}

A tradução do poema Malinche, de Rosario Castellanos, constitui-se em uma tradução múltipla: trata-se da tradução de um poema, evidentemente, mas, também, de uma mulher ainda não publicada no Brasil e de sua respectiva visão sobre uma história mítica que representa - ainda que distorcidamente - a América Latina. O objetivo, portanto, com essa tradução, foi dar a voz a duas mulheres: Rosario Castellanos e Malinche, ambas ainda injustiçadas, embora por motivos diferentes - Castellanos porque ainda não é enxergada pelo mercado editorial brasileiro, e Malinche porque ainda serve como bode expiatório para o depósito da culpa pela queda mexicana diante dos espanhóis e, consequentemente, por séculos da desigualdade que se instalaria nesse país.

A tradução do poema, embora não imponha extremas dificuldades técnicas, já que, por exemplo, não se estrutura por rimas, exige cuidado e atenção imprescindíveis para que se faça jus às vozes que falam, principalmente a de Malinche, historicamente silenciada. Portanto, embora não se trate de uma tradução extremamente intervencionista, buscou-se manter a voz de Castellanos, que precisa ser introduzida urgentemente, e com atraso, para o público brasileiro, mas com a presença de uma outra voz, a de quem traduz, que, em determinados momentos, como os aqui apresentados, interfere para manifestar-se no que, segundo a proposta de Godard (1989), representa "womanhandle the text", isto é, imprimir uma manipulação feminista na tradução.

Dessa forma, a releitura, a reescrita e a tradução feminista de Malinche buscam romper com a visão que a reduz a amante e traidora; procuram, pelo contrário, ao observar e destacar seu contexto - mulher em sociedade indígena comandada por homens e pautada por deuses, executora de sacrifícios humanos - e seu histórico de vida - renegada pela mãe, vendida e trocada como escravizada -, entender suas "escolhas" e motivações. Malinche passa, então, a ser o símbolo para o questionamento dos binarismos característicos da colônia e possibilita uma nova visão do período e das suas consequências para a sociedade mexicana e latino-americana. 


\section{Referências bibliográficas}

CASTELLANOS, Rosario. Poesía no eres tú: obra poética, 1948-1971. Fondo de Cultura Económica, 2004.

CASTRO, Olga. (Re)examinando horizontes en los estudios feministas de traducción: ¿hacia una tercera ola? MonTI, 1, 59-86, 2009.

CHAMBERLAIN, Lori. Gender and Metaphorics of Translation. Vol. 13. Chicago: Journals, 1988. pp. 454-472. Disponível em: <https://www.jstor.org/stable/3174168?origin=JSTOR-pdf\&seq=1>. Acesso em: 10 jun. 2020.

DÍAZ DEL CASTILLO, Bernal. Historia verdadera de la conquista de la Nueva España. 20. Ed. México: Editorial Porrúa, 2002.

ESQUIVEL, Laura. Malinche. Rio de Janeiro: Ediouro, 2006.

GODARD, Barbara. Theorizing Feminist Discourse/Translation. Tessera 6, 1989. pp. 42-53.

GUARDIA, Sara Beatriz. Literatura e escritura feminina na América Latina. Anais do XII Seminário Nacional e III Seminário Internacional Mulher e Literatura. Ilhéus: UESC, 2007.

RIOS CASTAÑO, Victoria. Fictionalising Interpreters: Traitors, Lovers and Liars in the Conquest of America. Linguistica Antverpiensia 4: 47-60, 2005.

SIMON, Sheery. Gender in Translation. Londres e Nova York: Routledge, 2005.

VON FLOTOW, L. Translation and Gender: Translating in the 'Era of Feminism'. University of Ottawa. Press, 1997. 